Article

\title{
The Effect of Service on Microstructure and Mechanical Properties of HR3C Heat-Resistant Austenitic Stainless Steel
}

\author{
Grzegorz Golański ${ }^{1}$, Adam Zieliński ${ }^{2}$, Marek Sroka ${ }^{3, * 0}$ and Jacek Słania ${ }^{4}$ \\ 1 Czestochowa University of Technology, Department of Materials Engineering, Armii Krajowej 19, \\ 42-200 Częstochowa, Poland; grzegorz.golanski@pcz.pl \\ 2 Łukasiewicz Research Network - Institute for Ferrous Metallurgy, K. Miarki 12-14, 44-100 Gliwice, Poland; \\ azielinski@imz.pl \\ 3 Department of Engineering Materials and Biomaterials, Silesian University of Technology, Konarskiego \\ St. 18a, 44-100 Gliwice, Poland \\ 4 Faculty of Mechanical Engineering and Computer Science, Czestochowa University of Technology, \\ Armii Krajowej 21, 42-200 Częstochowa, Poland; jacek_slania@poczta.onet.pl \\ * Correspondence: marek.sroka@polsl.pl; Tel.: +48-32-237-18-47
}

Received: 14 February 2020; Accepted: 11 March 2020; Published: 13 March 2020

check for updates

\begin{abstract}
The physical metallurgical tests were performed on the test samples made of HR3C steel, taken from a section of a pipeline in the as-received condition and after approximately 26,000 $\mathrm{h}$ of service at $550{ }^{\circ} \mathrm{C}$. In the as-received condition, the test material had austenitic microstructure with numerous large primary Z-phase precipitates inside the grains. The service of the test steel mainly contributed to the precipitation processes inside the grains and at the grain boundaries. After service, the following precipitates were identified in the microstructure of the test steel: Z-phase $(\mathrm{NbCrN})$ and $\mathrm{M}_{23} \mathrm{C}_{6}$ carbides. The Z-phase precipitates were observed inside the grains, whereas $\mathrm{M}_{23} \mathrm{C}_{6}$ carbides - at the boundaries where they formed the so-called continuous grid. The service of the test steel contributed to the growth of the strength properties, determined both at room and elevated temperature $\left(550,600{ }^{\circ} \mathrm{C}\right)$, compared to the as-received condition. Moreover, the creep properties of HR3C steel after service were higher than those of the material in the as-received condition. The increase in the strength properties and creep resistance was connected with the growth of strengthening of the test steel by the precipitation of Z-phase and $\mathrm{M}_{23} \mathrm{C}_{6}$ carbides.
\end{abstract}

Keywords: HR3C steel; precipitates; mechanical properties; creep resistance

\section{Introduction}

The HR3C steel belongs to a modern group of creep-resistant austenitic steels. This steel was developed as a result of modification of the chemical composition of steel 310 by adding the niobium and nitrogen microadditions and by optimizing the nickel content, which resulted in the growth of high-temperature creep strength and creep resistance while maintaining very high heat resistance. High creep resistance and very good resistance to high-temperature corrosion and oxidation in steam make the $\mathrm{HR} 3 \mathrm{C}$ steel the recommended material for the elements of supercritical power units, such as, but not limited to, boiler superheaters working at $650-660{ }^{\circ} \mathrm{C}[1,2]$.

The laboratory tests of HR3C steel made so far confirmed the assumed high corrosion resistance, but at the same time showed its susceptibility to very fast decrease in impact strength, with the cracking mechanism changed from ductile to brittle-intercrystalline [3-7]. The performed tests showed what was responsible for the low impact strength of $\mathrm{HR} 3 \mathrm{C}$ steel after ageing at above $600{ }^{\circ} \mathrm{C}$. It was the unfavourable morphology of the secondary phases $-\mathrm{M}_{23} \mathrm{C}_{6}$ carbides-precipitated at the grain 
boundaries, as well as the coarse-grained structure of the steel. Quick loss of ductility of HR3C steel indicates that the recommendation of the steel as the material for the boiler superheater pipes requires a certain amount of providence $[4,6,7]$. However, there is a lack of data concerning the HR3C steel behaviour during the actual service in the power unit. This paper presents the results of research on the structure and mechanical properties of the test samples taken from a section of the boiler superheater pipe made of $\mathrm{HR} 3 \mathrm{C}$ steel after service at $550{ }^{\circ} \mathrm{C}$.

\section{Material and Methodology of Research}

The tests were carried out on $25 \mathrm{Cr}-20 \mathrm{Ni}-\mathrm{Nb}-\mathrm{N}(\mathrm{HR} 3 \mathrm{C})$ creep-resistant austenitic steel. The tests samples were taken from a section of the steam superheater of $45 \mathrm{~mm}$ by $5.7 \mathrm{~mm}$. The tests were carried out on the material in the as-received condition and after approximately $26,000 \mathrm{~h}$ service at $550{ }^{\circ} \mathrm{C}$. The chemical composition of the test steel was determined using the SpectroLab spark spectrometer and are presented in Table 1.

Table 1. Chemical composition of the test steel, \%mass

\begin{tabular}{cccccccccc}
\hline $\mathbf{C}$ & $\mathbf{S i}$ & $\mathbf{M n}$ & $\mathbf{P}$ & $\mathbf{S}$ & $\mathbf{C r}$ & $\mathbf{N i}$ & $\mathbf{N b}$ & $\mathbf{N}$ & $\mathbf{C}$ \\
\hline 0.06 & 0.43 & 1.19 & 0.015 & 0.010 & 25.10 & 19.70 & 0.42 & 0.22 & 0.06 \\
\hline
\end{tabular}

The microscopic tests were performed on metallographic specimens etched with the Mi19Fe reagent, using the scanning electron microscope Jeol 6610LV (SEM) compatible with the chemical composition analyser X-Max Oxford Instruments (EDS). The metallographic specimens were taken perpendicularly to the axis of the pipe section. The analysis of precipitates was performed with the transmission electron microscope TITAN 80-300 using the selected area electron diffraction with thin foils. The $3 \mathrm{~mm}$ discs with thickness of 100-120 $\mu \mathrm{m}$ were electrolytically thinned to perforation using a solution of $20 \%$ perchloric acid in ethanol at $-30{ }^{\circ} \mathrm{C}$ and the applied voltage of $20 \mathrm{~V}$. The scope of the tests of mechanical properties included: Static tensile tests at room temperature and elevated temperature $\left(550,600^{\circ} \mathrm{C}\right)$ using flat test pieces with the original gauge width of $b_{o}=10 \mathrm{~mm}$-the testing machine Zwick/Roell Z250, and the accelerated creep tests at the test stress of $100 \mathrm{MPa}$ and temperatures of: $700,720,740,760$, and $780^{\circ} \mathrm{C}$. The detailed description of the accelerated creep test methodology is presented elsewhere, inter alia in [8].

\section{Test Results and Their Analysis}

In the as-received condition, the HR3C steel was characterised by a coarse-grained austenitic microstructure with irregular shape and large primary precipitates (Figure 1a,b). The vast majority of Z-phase particles were randomly distributed in the grains and a small amount was observed at the grain boundaries. Some of the particles in the test alloy were arranged as bands of precipitates.

These particles were identified as undissolved primary Z-phase. The typical morphology of the primary Z-phase is showed in Figure 2. As residual particles, these precipitates were formed during solidification and are undissolved by the solution treatment $[9,10]$. The Z-phase in the as-received HR3C steel was also observed by Zieliński [3], while Bai [6] and Peng [11] reported the presence of primary $\mathrm{Nb}$-rich MX particles in the as-received samples. The presence of primary precipitates in austenitic steels stabilised by microadditions of niobium or/and titanium is a typical feature of these materials. The primary precipitates of Z-phase are unfavourable precipitates in the microstructure of creep-resisting austenitic steels, since they do not have an influence on the precipitation strengthening due to their size. They can be places of potential nucleation and growth of creep cavities at the interphase precipitate/matrix boundary and block the precipitation of nanoscale $\mathrm{Nb}$-rich phase during creep/service [12]. In austenitic steels, the role of primary precipitates is limited to binding carbon atoms or/and nitrogen and impeding the grain growth during the thermo-plastic treatment. According to $[13,14]$, the primary precipitates in austenitic alloys may be transformed to 
harmful TCP (topologically close-packed) type phase(s) during service. Additionally, a number of annealing twins in the grains are observed. The twin boundaries in the austenite steel could improve the plasticity and ductility by interrupting the continuity of the austenite grain boundaries and relaxing the stress at the austenite grain boundaries [4,6]. According to [15], two types of twin substructures, coherent twins and incoherent twins are observed in HR3C steel. The coherent twins have straight sub-grain boundaries across the entire austenite, while incoherent twins are inside the austenite grain as shown in Figure 1, arrows two and three, respectively. No precipitates were observed at the grain boundaries and the twin boundaries.
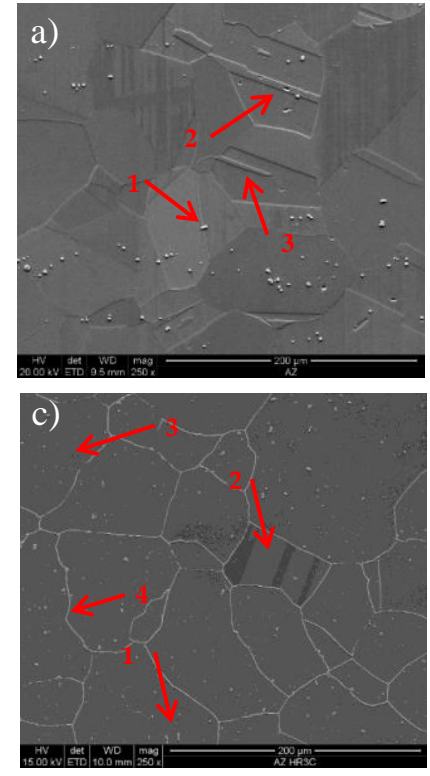
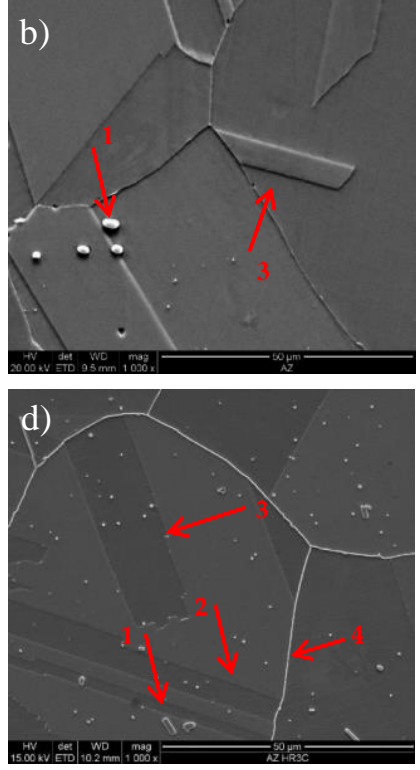

Figure 1. (a,b) microstructure of HR3C in the as-received condition, $(\mathbf{c}, \mathbf{d})$ microstructure of HR3C after service, 1-primary precipitates, 2-coherent twin, 3-incoherent twin, and 4-precipitates at the grain boundary; SEM.
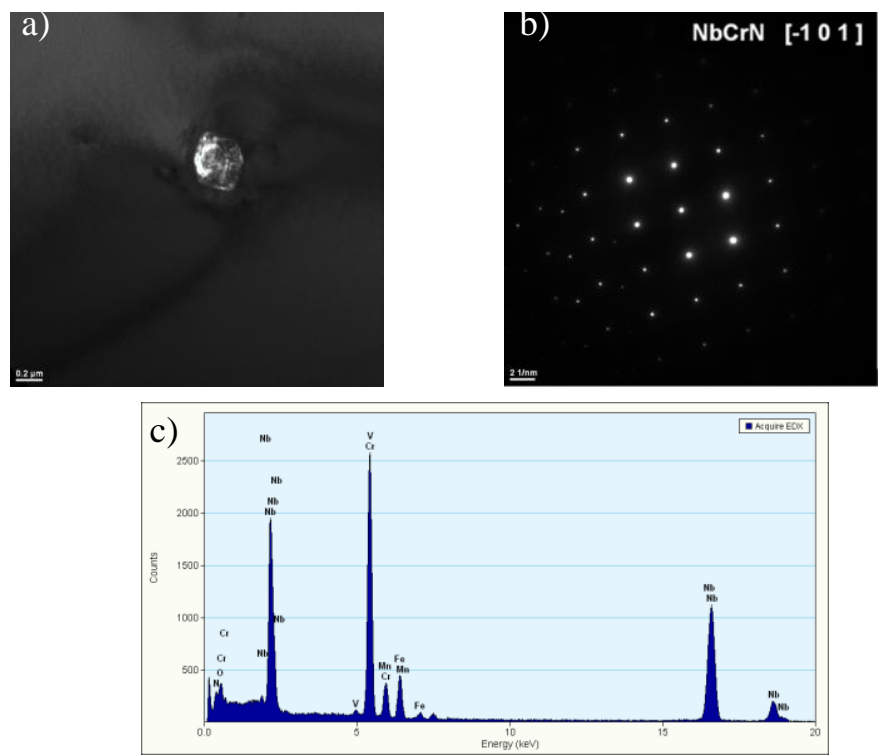

Figure 2. Primary Z-phase precipitate (a), resolved diffraction (b), EDS analysis (c); TEM.

The microstructure of HR3C steel after service is presented in Figure 1c,d. The results show that the service, compared to the as-received condition (Figure 1a,b), induced the excessive precipitation 
especially at the grain boundaries, and also inside the grains. Inside the grains, relatively numerous precipitates of varying size are visible, whereas at the grain boundaries the particles form the so-called continuous grid of precipitates (Figure 1c,d). The results of EDS analysis show that the precipitates at the grain boundaries are rich in chromium, however, inside the grains they are rich in chromium and niobium (Figures 3 and 4).
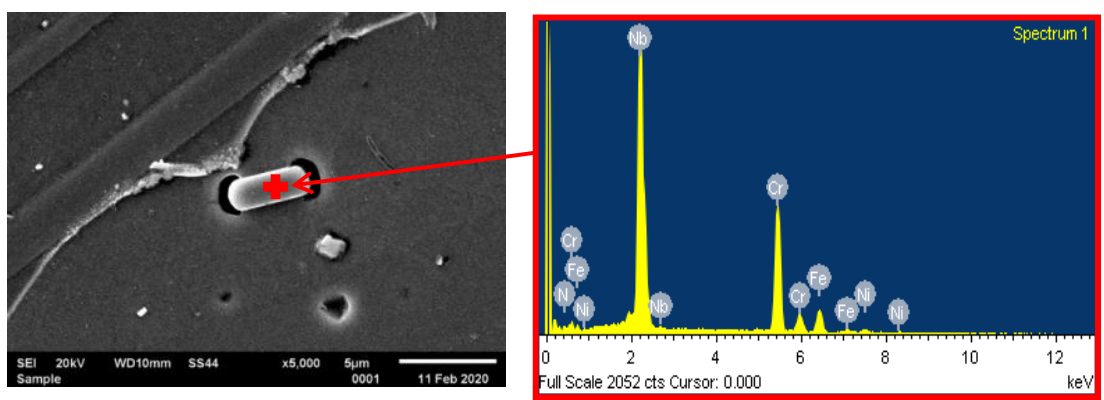

\begin{tabular}{llll}
\multicolumn{4}{l}{ Elements, $\mathrm{wt} \%$} \\
\hline $\mathrm{Cr}$ & $\mathrm{Fe}$ & $\mathrm{Ni}$ & $\mathrm{Nb}$ \\
\hline 41.54 & 14.40 & 2.66 & 41.40 \\
\hline
\end{tabular}

Figure 3. EDS analysis of precipitate inside the grain.

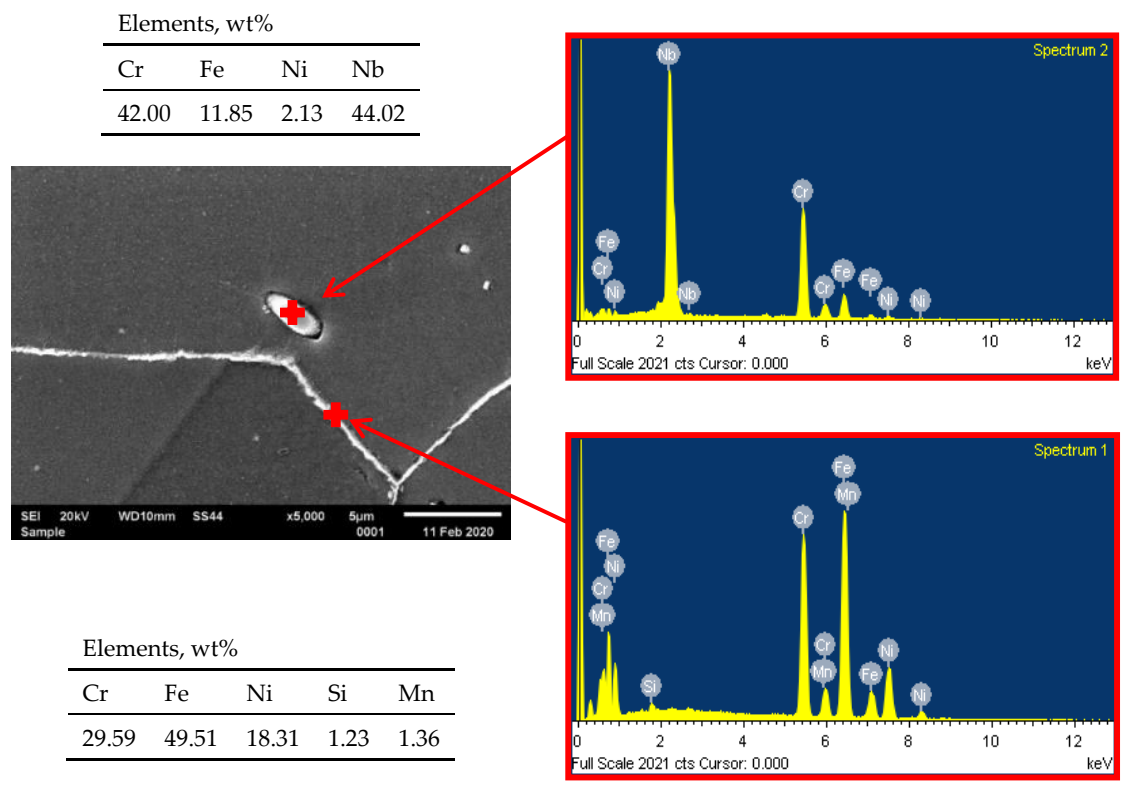

Figure 4. EDS analysis of precipitate inside the grain and at the grain boundary.

At the grain boundaries, these precipitates were identified as $\mathrm{Cr}$-rich $\mathrm{M}_{23} \mathrm{C}_{6}$ carbides (Figure 5), whereas inside the grains, as the secondary precipitates of $\mathrm{Nb}$ - and $\mathrm{Cr}$-rich Z-phase (Figure 6). In the alloys, like in the steels, the preferential place of precipitation of particles is the grain boundaries. As surface defects, the grain boundaries are characterised by higher interfacial energy compared to that inside the grain and at the twin boundaries. As defects with a disordered structure, the grain boundaries are also the areas that enhance faster diffusion of alloying atoms compared to the grain interior [10,16-18]. This allows for the preferred precipitation of $\mathrm{M}_{23} \mathrm{C}_{6}$ carbides at the grain boundaries. The $\mathrm{M}_{23} \mathrm{C}_{6}$ carbide precipitation process in austenitic steels is related to the reduction of carbon solubility with temperature [10]. Moreover, the precipitation of $\mathrm{M}_{23} \mathrm{C}_{6}$ carbides is a process of redistribution and reduction of the strain energy [6]. The $\mathrm{M}_{23} \mathrm{C}_{6}$ carbides precipitated at the grain boundaries in the austenitic steel can be observed as early as after around 1-h creeping at $600{ }^{\circ} \mathrm{C}[10,16]$. The fine 
$\mathrm{M}_{23} \mathrm{C}_{6}$ particles precipitated at the grain boundaries increase the creep resistance of austenitic steels by impeding the grain boundary sliding [9,10]. Prat et al. [19] found that the formation of nanosized $\mathrm{M}_{23} \mathrm{C}_{6}$ carbides could provide good creep resistance due to pinning effects of grain boundaries. The positive influence of this interaction depends on the stability of the particles precipitated at the boundaries and disappears with the growth of the particles.
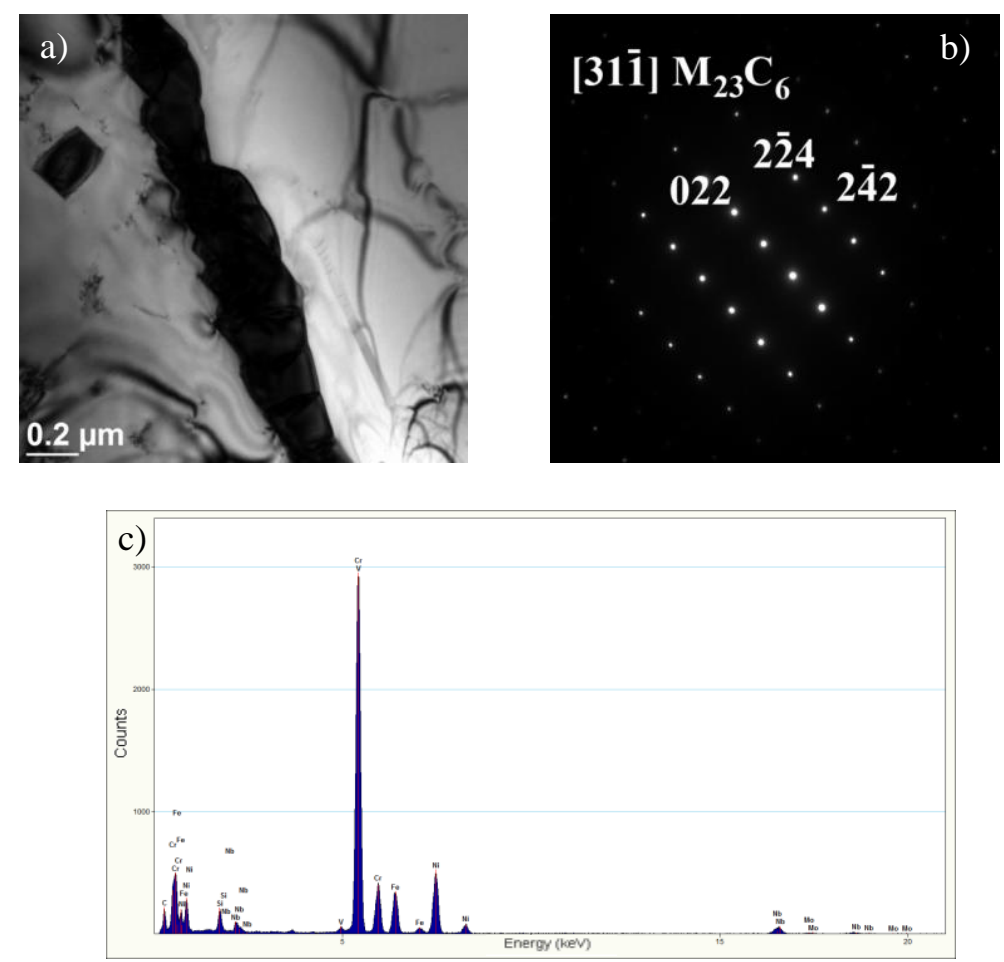

Figure 5. $\mathrm{M}_{23} \mathrm{C}_{6}$ carbides at the grain boundaries (a), resolved diffraction (b), EDS analysis (c); TEM.
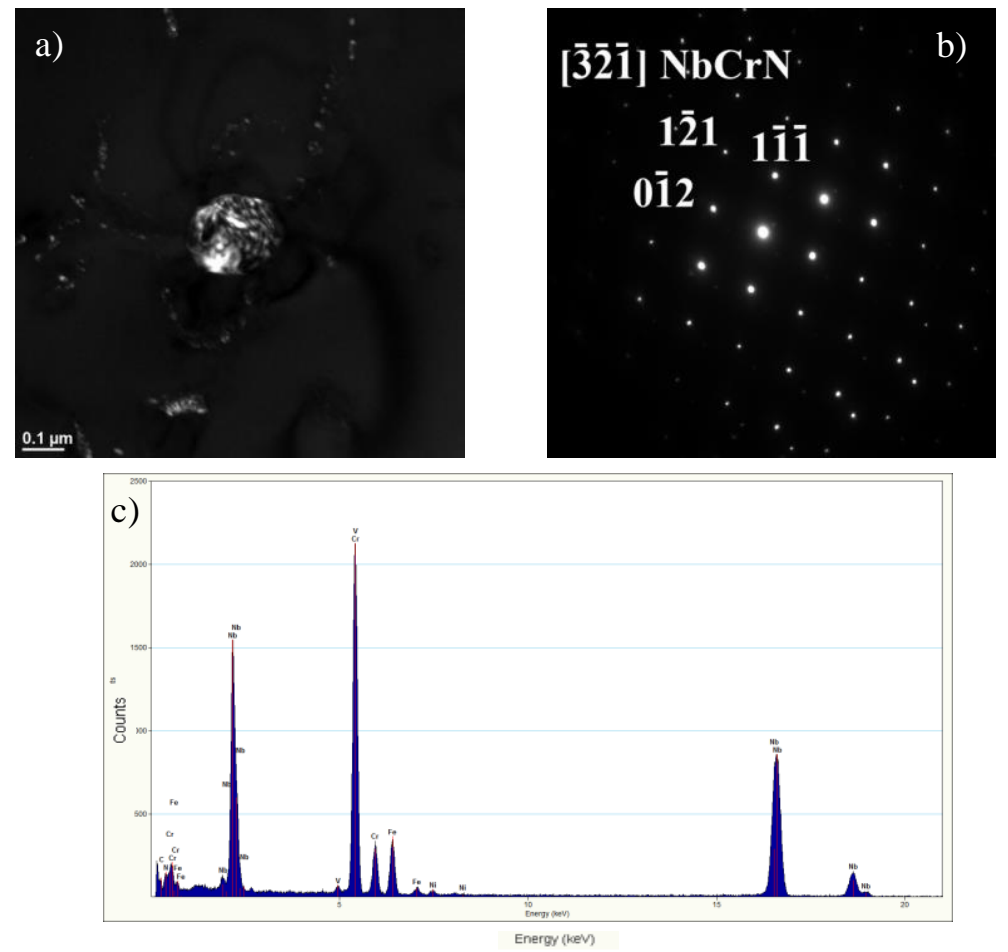

Figure 6. Secondary Z-phase (a), resolved diffraction (b), EDS analysis (c); TEM. 
However, $\mathrm{M}_{23} \mathrm{C}_{6}$ carbides are characterised by low thermodynamic stability $[10,15,19,20]$, and this contributes to an increase in both their amount and size at the boundaries, which results in the loss of this favourable impact. This rapid growth and coarsening of $\mathrm{M}_{23} \mathrm{C}_{6}$ carbides greatly widened the grain boundaries (Figure 7). The coarsening of $\mathrm{M}_{23} \mathrm{C}_{6}$ carbides at the grain boundaries is very harmful to the properties of the materials-increase in embrittlement and loss of the strengthening effect of particles [6,11]. The precipitation and growth of $\mathrm{M}_{23} \mathrm{C}_{6}$ carbides, $\mathrm{Cr}$-rich particles, at the grain boundaries may lead to the formation of chromium-depleted region near the grain boundaries [17,18]. When the content of chromium drops to the limit values needed for passivation, the intergranular corrosion will occur. Yan [21] suggests that the formation of depletion zone near the grain boundaries may affect a decrease in the local strength and promotes inhomogeneous deformation.

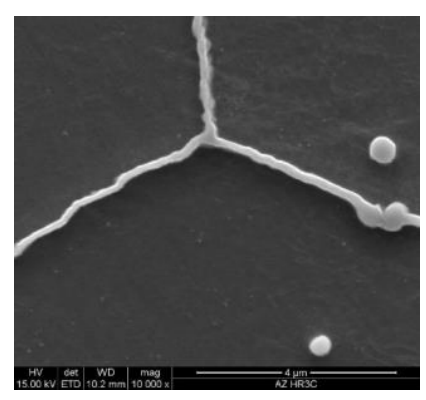

Figure 7. Widening of grain boundaries in HR3C steel after service.

Apart from the grain boundaries, the $\mathrm{M}_{23} \mathrm{C}_{6}$ particles can also gradually precipitate at the incoherent twin boundaries, coherent twin boundaries, and inside the grains. In the test steel after service, these precipitates were not observed at the twin boundaries (Figure 1c,d). The twin boundaries are characterised by low energy (3\%-10\% energy of the large-angle grain boundary), which results from the fact that the arrangement of atoms at both sides of the twin boundary is symmetric. Hence, the driving force for nucleation and growth of precipitates along the twin boundaries is lower than for the austenite grain boundaries [4]. The $\mathrm{M}_{23} \mathrm{C}_{6}$ precipitates were also not revealed inside the grains, which probably results from the relatively short time of service of the test steel.

Inside the grains, the secondary dispersive Z-phase precipitations were observed in the steel (Figures 6 and 8). The Z-phase particles can precipitate independently by the in situ mechanism or as a result of the local conversion of MX precipitates into the Z-phase, probably by a mechanism similar to the formation of this phase in $9 \%-12 \% \mathrm{Cr}$ martensitic steels [22,23]. The Z-particles precipitate near the grain boundaries and also on the dislocations. Similarly, the precipitation of secondary Z-phase particles occurs in areas with high dislocation density, which results not only in the pile-up of dislocations, but also in the aggregation of precipitates (Figure 8). According to the Orowan law, the fine-dispersion Z-phase precipitates and their relatively high stability make the particles/aggregates effectively prevent the motion of dislocations and have an intensive pinning strengthening effect $[10,11,23,24]$.

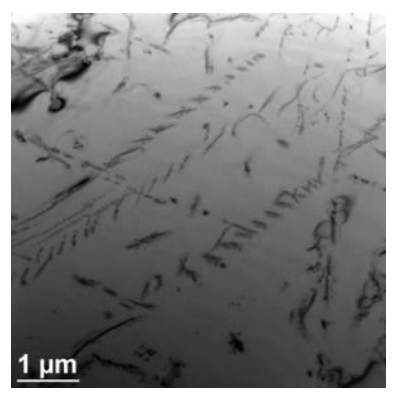

Figure 8. Z-phase aggregation precipitates inside the austenite grain. 


\section{Mechanical Properties of HR3C Steel after Service}

In general, the purpose of the high-temperature solution treatment of the creep-resistant austenitic steels by dissolving the secondary phases was to obtain a single-phase structure. The structure of austenitic steels in the as-received condition (Figure 1a,b) provides high plasticity (and also ductility [3]) with the relatively low strength properties - the yield strength (YS) and tensile strength (TS) (Figure 9a). High plasticity of austenitic steels in the as-received condition results, among other things, from their solid solution strengthening and a large number of slip bands [3,4].
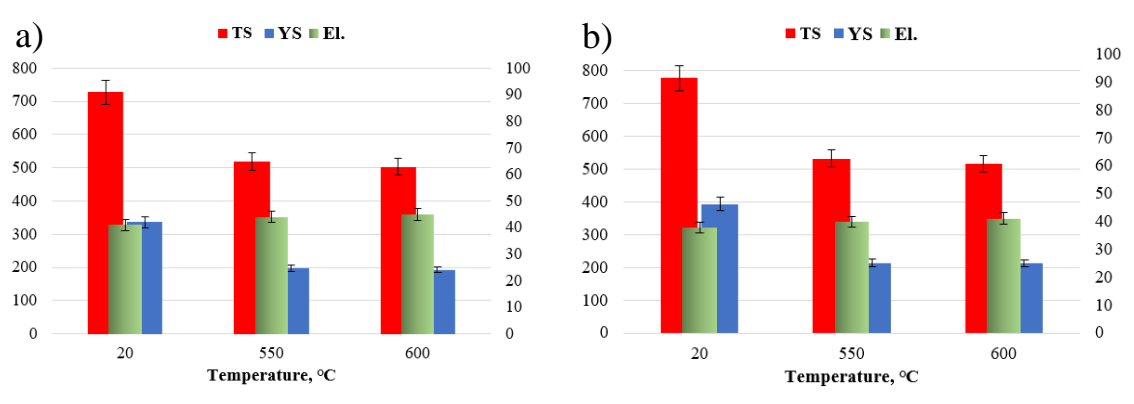

Figure 9. Mechanical properties of HR3C steel in as-received condition (a) and after service (b); YS-yield strength, TS—-tensile strength, and El.-elongation.

The total strength of austenitic steels is governed by different strengthening mechanisms: Mainly precipitation and also solid solution strengthening $[9,10]$. The secondary phase precipitation processes (Figures 5 and 6) that take place during the service lead to a considerable increase in precipitation strengthening of the creep-resistant austenitic steels. The strength properties, hardness, and creep properties of the steel are known to depend mainly on the size, number, and volume fraction of the secondary particles. Small size and great number of the precipitated phase cause a significant growth of precipitation hardening. In the precipitation strengthening of steels, two mechanisms of interaction between the dislocations and the secondary phase particles can be observed: The Orowan mechanism and the cutting mechanism. In the creep-resistant steels, the dominant mechanism of interaction between the dislocations and the precipitates, causing the strengthening of these alloys, is the Orowan mechanism, because the precipitates in this group of materials are regarded as too hard to be cut by dislocations $[4,11]$. In the test steel after service, the value of the TS, regardless of the test temperature, was higher than the required one, while maintaining the plasticity (elongation (El.)) above the minimum value (Figure 9). In the test steel after service, two types of secondary precipitates were observed: $\mathrm{M}_{23} \mathrm{C}_{6}$ carbides and Z-phase (Figures 5 and 6), therefore, the high strength properties should be associated with the occurrence of the precipitation strengthening by these precipitates. The dispersive form of the secondary precipitates of the Z-phase (Figures 6 and 8) and the around 10-fold higher stress of the pinning force of this phase, compared to that of the $\mathrm{M}_{23} \mathrm{C}_{6}$ carbides, according to $[11,24]$, is responsible in $75 \%$ for the effect of precipitation strengthening in austenitic steel. A similar effect was observed in $\mathrm{P} 91$ steel, where the stress required to bypass the primary $\mathrm{NbC}$ precipitate by the Orowan mechanism amounted to $16 \mathrm{MPa}$, whereas for the secondary VX precipitate-106 $\mathrm{MPa}$, and for the $\mathrm{M}_{23} \mathrm{C}_{6}$ carbide-39 MPa [25]. Compared to $\mathrm{M}_{23} \mathrm{C}_{6}$ carbides, the Z-phase precipitates are characterised by a relatively more dispersive form and higher stability $[9,10]$. This makes them more effective barriers to the dislocation movement, assuming the Orowan mechanism effect. Moreover, part of the Z-phase particles are precipitated at the dislocations, which results in the pile-up of the dislocations-Figure 8. A similar favourable influence of the dispersive secondary precipitates on the considerable growth of YS in Super $304 \mathrm{H}$ steel, or TP 347 steel, was observed respectively in [26,27] and [28]. However, the significant influence of $\mathrm{M}_{23} \mathrm{C}_{6}$ carbides on $\mathrm{YS}$ at elevated temperature was pointed out by the authors of [29]. At the same time, during service at elevated temperatures, a gradual decrease in the concentration of solute elements occurs in the austenitic matrix [30], which translates 
into a reduction in effect of solid solution strengthening mechanism on the strength properties of the steel. This indicates that the increase in strength-YS and TS of the steel is mainly controlled by the precipitation strengthening mechanism. This shows that the dominant factor that affects the growth of strengthening translating into the increase in YS in HR3C steel is not only the presence of precipitates of the secondary Z-phase, but probably also of the $\mathrm{M}_{23} \mathrm{C}_{6}$ carbides. The strengthening effect associated with the Z-phase particles, and also probably with the $\mathrm{M}_{23} \mathrm{C}_{6}$ carbides, prevents the softening of the steel due to depletion of solid solution. The extent of strengthening will depend on the dispersion of these precipitates - the number, size, and shape. Trotter and Baker [31] show that the YS is controlled by the interparticle spacing in the grain interior. The increase in strength properties of the test steel during service results in a relatively slight reduction in yield strength-El. compared to the as-received condition (Figure 9). The reduction in El. is probably related to both the effects of the secondary precipitates/dislocations and to the likely decrease of twins density. According to [7,21], one of the effects of the influence of temperature on the microstructure of austenitic steels is the loss of twins. In the opinion of [32], the relatively high El. of HR3C steel after service may result from the grain rotation during deformation, which is probably related to the formation of the chromium-depleted area adjacent to the grain boundaries.

The rise in test temperature results in the reduction in TS value by almost half compared to the as-received condition (Figure 9). Wang et al. [33] reported that at $650{ }^{\circ} \mathrm{C}$ fast diffusion could assist dislocation in bypassing nanosized precipitates by means of climbing. With the decreasing interaction between the precipitates and the matrix, the precipitate strengthening gradually weakened and the tensile strength subsequently decreased. Xiao et al. [34] also reported that this phenomenon might be related to sub-grain coarsening and decreasing in dislocation density.

The factor deciding about the fitness of the material used, among other things, for the steam pipelines is the resistance to creep. The results of short-term creep tests of the test steel are presented in Figure 10. In the engineering practice, short-term creep tests are used to determine the time of further safe operation of the steel types serviced beyond the design service time [8]. The determination of residual life by the short-term creep tests provides knowledge about the actual possibility of further safe service of the given material and allows the time of further safe operation to be determined.

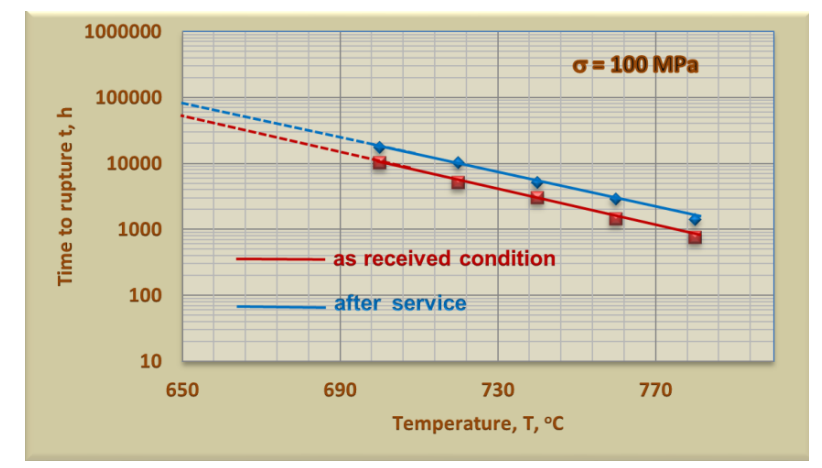

Figure 10. Results of short-term creep test of HR3C steel.

The creep strength of the elements of power units made of HR3C steel determined in the short-term creep tests, while maintaining the previous parameters, was higher than that of the material in the as-received condition. This effect, similarly, as in the case of the determined strength properties, was related to the occurrence of precipitation strengthening. In case of creep properties of the HR3C steel, it is determined by the dispersion and stability of the dominant precipitates in this alloy, i.e., the $\mathrm{Z}$-phase particles, as well as the $\mathrm{M}_{23} \mathrm{C}_{6}$ carbides. The dispersive form of the Z-phase particles often precipitates at the dislocations [9-11,23,28], which enables their pinning, and their high thermodynamic stability $[9,10]$ ensures the effective impeding of the free dislocation movement for a long time. Observed in the microstructure, the relatively fine $\mathrm{M}_{23} \mathrm{C}_{6}$ precipitates at the grain boundaries probably 
also have an influence on the increase in the creep rate limiting through the slide on the boundaries of grains. However, at elevated/high temperature, the mobility of dislocations grows and they can bypass the precipitates through climbing and cross slip, which limits the precipitation strengthening by Orowan mechanism. In addition to the precipitation hardening, an important factor that affects the creep properties of austenitic stainless steel is, according to [20], the solid solution strengthening by nitrogen atoms.

\section{Summary}

The service of HR3C steel at the temperature lower than the long-term service temperature expected for this grade contributed to changes in the microstructure, reflected mostly in the precipitation processes. In the microstructure, the precipitation processes were observed at the grain boundaries and inside the grains. However, no precipitates at the twin boundaries were revealed. The precipitates at the grain boundaries formed the so-called continuous grid of precipitates. The presence of numerous chromium-rich precipitates in the microstructure of the test steel, the $\mathrm{M}_{23} \mathrm{C}_{6}$ carbides at the grain boundaries and the dispersive Z-phase precipitates inside the grains was observed. In the test steel, the precipitation processes resulted in the growth of strength properties and creep resistance through the precipitation strengthening mechanism. The effect of this strengthening mechanism depends on the stability and dispersion of the secondary precipitates. Controlling the precipitations and growth of the Z-phase and $\mathrm{M}_{23} \mathrm{C}_{6}$ carbides is beneficial to the enhancement of the strength and creep properties.

Author Contributions: G.G. conceived and designed the experiments; A.Z. performed the experiments; J.S. analyzed the data; G.G. and M.S. wrote the paper-review and editing. All authors have read and agreed to the published version of the manuscript.

Funding: This research received no external funding.

Conflicts of Interest: The authors declare no conflicts of interest.

\section{References}

1. Chi, C.; Yu, H.; Xie, X. Advanced Austenitic Heat-Resistant Steels for Ultra-Super-Critical (USC) Fossil Power Plants. In Alloy Steel-Properties and Use; Morales, E.V., Ed.; InTech: Rijeka, Croatia, 2011; pp. 171-201.

2. Iseda, A.; Okada, H.; Semba, H.; Igarashi, M. Long term creep properties and microstructure of SUPER304H, TP347HFG and HR3C for A-USC boilers. Energy Mater. 2007, 2, 199-206. [CrossRef]

3. Zieliński, A.; Sroka, M.; Hernas, A.; Kremzer, M. The effect of long-term impact of elevated temperature on changes in microstructure and mechanical properties of HR3C steel. Arch. Metall. Mater. 2016, 61, 761-765. [CrossRef]

4. Wang, B.; Liu, Z.-D.; Cheng, S.-C.; Liu, C.-M.; Wang, J.-Z. Microstructure evolution and mechanical properties of HR3C steel during long-term aging at high temperature. J. Iron Steel Res. Int. 2014, 21, 765-773. [CrossRef]

5. Wang, W.; Wang, Z.; Li, W.; Tian, J.; Zhong, W.; Lin, J. Evolution of $\mathrm{M}_{23} \mathrm{C}_{6}$ phase in HR3C steel aged at $650{ }^{\circ} \mathrm{C}$. Mater. High Temper. 2016, 33, 276-282. [CrossRef]

6. Wei, L.; Hao, W.; Cheng, Y.; Tan, S. Isothermal aging embrittlement in an Fe-22Cr-25Ni alloy. Mater. Sci. Eng. A 2018, 737, 40-46. [CrossRef]

7. $\mathrm{Hu}, \mathrm{Z} .-\mathrm{F}$; Zhang, Z. Investigation the effect of precipitating characteristic on the creep behavior of HR3C austenitic steel at $650{ }^{\circ} \mathrm{C}$. Mat. Sci. Eng. A 2019, 742, 451-463. [CrossRef]

8. Zieliński, A.; Golański, G.; Sroka, M.; Dobrzański, J. Estimation of long-term creep strength in austenitic power plant steels. Mater. Sci. Technol. 2016, 32, 780-785. [CrossRef]

9. Golański, G.; Zielińsk, A.; Purzyńsk, H. Precipitation process in creep-resistant austenitic steels. In Austenitic Stainless Steels; Borek, W., Tański, T., Brytan, Z., Eds.; InTech: Rijeka, Croatia, 2017; pp. 93-112.

10. Zhou, Y.; Liu, Y.; Zhou, X.; Liu, C.; Yu, J.; Huang, Y.; Li, H.; Li, W. Precipitation and hot deformation behavior of austenitic heat-resistant steels: A review. J. Mater. Sci. Technol. 2017, 33, 1448-1456. [CrossRef] 
11. Peng, B.; Zhang, H.; Hong, J.; Gao, J.; Zhang, H.; Li, J.; Wang, Q. The evolution of precipitates of 22Cr-25Ni-Mo-Nb-N heat-resistant austenitic steel in long term creep. Mater. Sci. Eng. A-Struct. 2010, 527, 4424-4430. [CrossRef]

12. Sklenicka, V.; Kucharova, K.; Kvapilova, M.; Svoboda, M.; Kral, P.; Dvorak, J. Creep properties of simulated heat-affected zone of HR3C austenitic steel. Mater. Charact. 2007, 128, 238-247. [CrossRef]

13. Sun, W.; Qin, X.; Guo, L.L.; Zhou, L. Thermal stability of primary MC carbide and its influence on the performance of acst Ni-base superalloys. Mater. Des. 2015, 69, 81-88. [CrossRef]

14. Guo, X.; Jia, X.; Gong, J.; Geng, L.; Tang, J.; Jiang, Y.; Ni, Y.; Ynag, X. Effect of long-term aging on microstructure stabilization and mechanical properties of 20Cr32Ni1Nb steel. Mater. Sci. Eng. A 2017, 690, 62-70. [CrossRef]

15. Zhang, Z.; Hu, Z.; Tu, H.; Schmauder, S.; Wu, G. Microstructure evolution in HR3C austenitic steel during long-term creep at $650{ }^{\circ} \mathrm{C}$. Mater. Sci. Eng. A 2017, 681, 74-84. [CrossRef]

16. Jones, R.; Randle, V.; Owen, G. Carbide precipitation and grain boundary plane selection in overage type 316 austenitic stainless steel. Mater. Sci. Eng. A 2008, 496, 256-261. [CrossRef]

17. Terada, M.; Escriba, D.M.; Costa, I.; Materna-Morris, E.; Padliha, A.F. Investigation on the intergranular corrosion resistance of the AISI 316L(N) stainless steel after long time creep testing. Mater. Charact. 2008, 59, 663-668. [CrossRef]

18. Kaneko, K.; Futunaga, T.; Yamada, K.; Nakada, N.; Kikuchi, M.; Saghi, Z.; Barnad, J.S.; Midgley, P.A. Formation of $\mathrm{M}_{23} \mathrm{C}_{6}$-Type precipitates and chromium-depleted zone in austenite stainless steel. Scr. Mater. 2011, 65, 509-512. [CrossRef]

19. Prat, O.; Garcia, J.; Rojas, D.; Carrasco, C.; Kaysser-Pyzall, A.R. Investigations on coarsening of MX and $\mathrm{M}_{23} \mathrm{C}_{6}$ precipitates in $12 \% \mathrm{Cr}$ creep resistant steels assisted by computational thermodynamics. Mater. Sci. Eng. A 2010, 527, 5976-5983. [CrossRef]

20. Vujic, S.; Standströ, R.; Sommitsch, C. Precipitation evolution and creep strength modeling of $25 \mathrm{Cr} 20 \mathrm{NiNbN}$ austenitic steel. Mater. High Temp. 2015, 32, 607-618. [CrossRef]

21. Yan, J.; Gu, Y.; Sun, F.; Xu, Y.; Yuan, Y.; Lu, Y.; Yang, Z.; Dang, Y. Evolution of microstructure and mechanical properties of a 25Cr-20Ni heat resistant alloy after long-term. Mater. Sci. Eng. A 2016, 675, 289-298. [CrossRef]

22. Danielsen, H.K.; Hald, J. Influence of Z-phase on long-term creep stability of martensitic 9 to $12 \% \mathrm{Cr}$ steels. VGB PowerTech. 2009, 5, 68-73.

23. Li, Y.; Liu, Y.; Liu, C.; Li, C.; Li, H. Mechanism for the formation of Z-phase in $25 \mathrm{Cr}-20 \mathrm{Ni}-\mathrm{Nb}-\mathrm{N}$ austenitic stainless steel. Mater. Lett. 2018, 233, 16-19. [CrossRef]

24. Zhao, J.; Wang, H.; Cheng, C.-Q.; Fang, Y.Y.; Li, X.-N. Precipitation in 25Cr20NiNbN austenitic steel after ageing at $750{ }^{\circ} \mathrm{C}$. Mater. High Temp. 2015, 32, 461-466. [CrossRef]

25. Magnusson, H.; Sandstrom, R. Influence of aluminium on creep strength of $9-12 \%$ Cr steels. Mater. Sci. Eng. A 2009, 527, 118-125. [CrossRef]

26. Yang, Y.; Zhu, L.; Wang, Q.; Zhu, C. Microstructural evolution and the effect on hardness and plasticity of S31042 heat-resistant steel during creep. Mater. Sci. Eng. A 2014, 608, 164-173. [CrossRef]

27. Wang, H.; Li, Y.; Chen, D.; Sun, J. Precipitate evolution the ageing of Super304H steel and its influence on impact toughness. Mater. Sci. Eng. A 2019, 754, 238-245. [CrossRef]

28. Solenthaler, C.; Ramesh, M.; Uggowitzer, P.J.; Spolenak, R. Precipitattion strengthening of Nb-stabilized TP347 austenitic steel by a dispersion of secondary $\mathrm{Nb}(\mathrm{C}, \mathrm{N})$ formed upon a short-term hardening heat treatment. Mater. Sci. Eng. A 2015, 647, 294-302. [CrossRef]

29. Peng, B.; Zhang, H.; Hong, J.; Gao, J.; Zhang, H.; Wang, Q.; Li, J. The effect of $\mathrm{M}_{23} \mathrm{C}_{6}$ on the high-temperature tensile strength of two austenitic heat-resistant steels: $22 \mathrm{Cr}-25 \mathrm{Ni}-\mathrm{Mo}-\mathrm{Nb}-\mathrm{N}$ and $25 \mathrm{Cr}-20 \mathrm{Ni}-\mathrm{Nb}-\mathrm{N}$. Mater. Sci. Eng. A 2011, 528, 3625-3629. [CrossRef]

30. Nikulin, I.; Kipelova, A.; Kaibyshev, R. Effect of high-temperature exposure on the mechanical properties of 18Cr-8Ni-W-Nb-V-N stainless steel. Mater. Sci. Eng. A 2012, 554, 61-66. [CrossRef]

31. Trotter, G.; Baker, I. The effect of aging on the microstructure and mechanical behavior of the alumina-forming austenitic stainless steel Fe-20Cr-30Ni-2Nb-5Al. Mater. Sci. Eng. A 2015, 627, 270-276. [CrossRef]

32. Yan, J.; Gu, Y.; Sun, F.; Michinari, Y.; Zhong, Z.; Yuan, Y.; Lu, J. Microstructural study in a Fe-Ni-base superalloy during creep-rupture at intermediate temperature. Mater. Sci. Eng. A 2015, 639, 15-20. [CrossRef] 
33. Wang, L.; Li, M.; Almer, J. In situ characterization of Grade 92 steel during tensile deformation using concurrent high energy X-ray diffraction and small angle X-ray scattering. J. Nucl. Mater. 2013, 440, 81-90. [CrossRef]

34. Xiao, B.; Xu, L.; Lei, Z.L.; Han, Y.D. Tensile mechanical properties, constitutive equations, and fracture mechanisms of a novel $9 \%$ chromium tempered martensitic steel at elevated temperatures. Mater. Sci. Eng. A 2017, 690, 104-119. [CrossRef]

(C) 2020 by the authors. Licensee MDPI, Basel, Switzerland. This article is an open access article distributed under the terms and conditions of the Creative Commons Attribution (CC BY) license (http://creativecommons.org/licenses/by/4.0/). 